\title{
ROBOT PENGHINDAR HALANGAN BERBASIS MIKROKONTROLER
}

\section{ATMEGA8535}

\author{
Woro Agus Nurtiyanto ${ }^{1}$, Ahmad Hindasyah, S.Si, M.Si ${ }^{2}$. Kartika Sekarsari, ST $^{3}$. \\ 1,2,3 Prodi Teknik Elektro UNPAM \\ Jln. Puspiptek Raya No 46 Buaran, Setu - Tangerang Selatan 15310 \\ E-mail :bags.haiker@gmail.com
}

\begin{abstract}
ABSTRAK
Perkembangan teknologi automatik parkir dikembangan oleh industri automotif. Parkir sembarangan sering terjadi benturan antar mobil yang sedang terparkir dangan mobil yang akan diparkir. Oleh karena itu penulis memiliki pemikiran tentang robot penghindar halangan sengaja dirancang untuk dapat menghindari penghalang yang berada disekitarnya. Tujuan penulis adalah merancang robot penghidar halangan berbasis mikrokontroler sebagai ide terapan pada mobil sebagai aplikasi deteksi penghalang ketika parkir secara automatik. Robot penghindar halangan ini dibuat dengan tiga bagian utama, yaitu masukan menggunakan sensor ultrasonik,sistem pengendali menggunakan mikrokontroler 8535 , dan sistem actuator menggunakan motor dc. Robot ini dirancang dengan sistem kemudi roda diferensial, yaitu masing-masing motor untuk kemudi roda kanan dan roda kiri. Penempatan sensor ultrasonik adalah pada bagian depan, kanan dan kiri agar robot dapat berjalan untuk menghindari halangan yang berada di sekitarnya. Antarmuka serial yang digunakan pada robot, berfungsi untuk mendapatkan jarak antara robot dengan objek penghalang disekitarnya. Pengujian robot dilakukan dengan menempatkan robot pada suatu kondisi dengan posisi penghalang yang berbeda-beda. Dari hasil pengujian yang dilakukan terhadap robot, dan melalui analisa data dan grafik, robot mampu menghindari halang berbahan berbeda mulai dari bahan kayu, dinding, dan bahan lainnya sesuai jarak $2-4 \mathrm{~cm}$ dapat berfungsi dengan baik.
\end{abstract}

Kata kunci : Robot penghindar halangan, sensor ultrasonik, mikrokontroler.

\begin{abstract}
The development of automatic parking technology developed by the automotive industry. Indiscriminate parking is often a collision between cars that are parked with cars to be parked. Therefore the authors have thoughts about robot avoidance obstacles deliberately designed to be able to avoid the obstacles that are nearby. The purpose of the authors is to design a microcontroller based obstruction hindrance robot as an applied idea on the car as an application of barrier detection when parking automatically. This obstacle avoidance robot is made with three main parts, ie input using ultrasonic sensor, controlling system using 8535 microcontroller, and actuator system using dc motor. The robot is designed with a differential wheel steering system, ie each motor for the right wheel steering and the left wheel. Placement of ultrasonic sensors is on the front, right and left so that the robot can run to avoid obstacles that are in the vicinity. Serial interface used on the robot, serves to get the distance between the robot with the surrounding obstructing object. Robot testing is done by placing the robot in a condition with different barrier positions. From the results of tests conducted on robots, and through analysis of data and graphics, the robot is able to avoid different things made from wood, walls, and other materials in accordance with the distance $2-4 \mathrm{~cm}$ can function properly.
\end{abstract}

Keywords: Robot avoidance obstruction, ultrasonic sensor, microcontroller. 


\section{PENDAHULUAN}

Mobil kendaran keluarga yang memuat banyak penumpang, kendaran dikendalikan pengemudi, dimana pengemudi adalah pengendali kendaraan apakah kendaraan tersebut berjalan normal atau tidak, dari itu lah terlihat bahwa perlu adanya modifikasi atau pengembangan dalam teknologi kendali kendaran yang sangat membantu guna keselamatan pengendara. sekarang ini automatik parking sudah dikembangkan di perusahan automotif seperti hundai, kia dan perusahaan automotif lainnya. kedepan perkembangan teknologi kecerdasan buatan akan diterapan pada kendaraan beroda dalam membantu pengemudi untuk mengendalikan kendaran.

Perancang robot penghidar halangan berbasis mikrokontroler 8535 sebagai ide terapan pada mobil sebagai aplikasi deteksi penghalang ketika parkir secara automatik, masih banyak orang yang kesulitan dalam melakukan parkir beruntun di tempat tempat parkir yang tersedia. kedepannya diperlukan kecerdasan buatan dalam pengembangan.

Robot penghindar halangan ini dibuat dengan tiga bagian utama, yaitu masukan menggunakan sensor ultrasonik, sistem pengendali menggunakan mikrokontroler 8535, dan sistem actuator menggunakan 1 motor dc. Robot ini dirancang dengan sistem 2 . kemudi roda diferensial, yaitu masingmasing motor untuk kemudi roda kanan dan roda kiri. Penempatan sensor ultrasonik adalah pada bagian depan, kanan dan kiri agar robot dapat berjalan untuk menghindari halangan yang berada di sekitarnya. Antarmuka serial yang digunakan pada robot, berfungsi untuk mendapatkan jarak antara robot dengan objek penghalang disekitarnya. Pengujian robot dilakukan dengan menempatkan robot pada suatu kondisi dengan posisi penghalang yang berbeda-beda.

Berkaitan dengan hal tersebut, dalam penelitian ini dibuat sebuah rancang bangun robot penghindar halangan berbasis mikrokontroler AT-MEGA 8535, menghindari halangan dengan masukkan dari sensor tertentu, Aktuator menggunakan motorDC dengan menggunakan sistem pengendali aktuator Rangkaian Simulasi $\mathrm{H}$ Bridge .

\section{TEORI}

\section{Robot Avoider}

Robot avoider adalah robot beroda atau berkaki yang diprogram untuk dapat menghindar jika ada halangan, misalnya dinding. Robot avoider minimal membutuhkan tiga buah sensor untuk mendeteksi penghalang yaitu sensor depan, kanan dan kiri. Dalam hal ini sensor yang dipergunakan adalah sensor ultrasonik.

Robot membutuhkan sensor yang banyak untuk hasil pendeteksian penghalang yang lebih baik. $\mathrm{Hal}$ ini dikarenakan keterbatasan sudut pancaran sensor ( biasanya sekitar 15 derajat saja ). Sudut pantulan yang terlalu besar akan menyebabkan hasil pembacaan sensor yang kurang akurat. Robot avoider adalah cikal bakal dari robot pemadam api dimana konsep dari robot avoider ini dapat berubah menjadi robot pemadam api dengan menambahkan sensor UVtron ke dalam robot ini maka akan menjelma menjadi robot pemadam api. Untuk membuat robot pemadam api tidaklah sulit yaitu dengan menambahkan sensor UVtron kedalam robot avoider. Sistem minimal robot avoider adalah sebagai berikut :

Mikrokontroller ATMega 8535

3 bh sensor pendeteksi penghalang ultrasonik )

3. 2 buah motor dc sebagai penggerak roda Untuk menjadi sebuah robot yang cerdas maka konsep robot avoider tadi dapat diubah menjadi robot pemadam api, yaitu dengan memberikan tambahan sebuah sensor pendeteksi api yaitu flame detector ( Uvtron ).

\section{Prinsip Dasar dari Navigasi Robot}

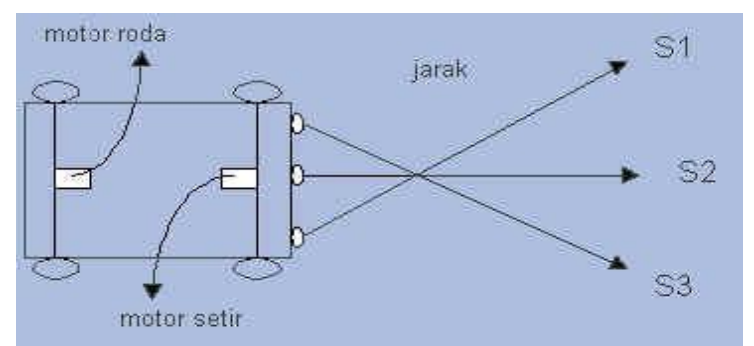

Gambar 1. Contoh mobill $\operatorname{robot}^{8}$ 
Motor roda yang terpasang pada bagian belakang dari robot mobil dipakai untuk mengatur kecepatan dari gerak maju / mundur robot mobil, sedangkan motor setir digunakan untuk mengontrol arah dan besar dari sudut belokan. Ada 3 buah sensor ultrasonik sebagai sensor jarak yang diletakkan di bagian depan dari robot mobil. Peletakan sensor ultrasonik secara bersilangan dimaksudkan agar :

a. Dapat mendeteksi besarnya halangan yang berada didepannya sehingga dapat menghindari halangan tersebut dengan baik.

b. Masih mampu mendeteksi adanya belokan walaupun robot mobil sudah terlalu berdekatan dengan salah satu sisi dari jalur jalan

c. Pendeteksian terhadap adanya belokan dari jarak yang masih jauh lebih baik karena mempunyai sudut pantulan yang lebih kecil jika dibandingkan dengan jika dipasang secara tidak bersilangan.

Perencanaan rules

Cara penentuan rules dapat dijelaskan sebagai berikut :

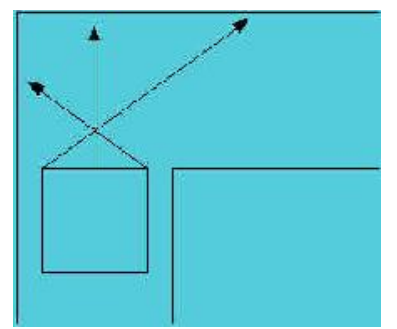

Gambar 2. Penentuan Rule Belok ${ }^{9}$

Pada kondisi ini diperoleh :

1. Sensor kanan mendeteksi jarak mobil dengan jalur kiri sangat dekat sehingga dapat dikatakan " Kanan is Very_Near".

2. Sensor kiri mendeteksi jarak mobil dengan jalur kanan sangat jauh (karena ada belokan) sehingga dapat dikatakan " Kiri is Very_Far".

3. Sensor tengah mendeteksi jarak mobil dengan jalur depan sangat dekat sehingga dapat dikatakan " Tengah is Very_Near".

Dari ketiga keadaan ini dapat dijadikan suatu rule yang dinyatakan sebagai : "If Kanan is Very_Near and Tengah is
Very_Near and Kiri is Very_Far then Setir is Very_Positif and Speed is Slow ". Very_Positif disini diartikan sebagai setir akan mempunyai prioritas belok kearah kanan dan Slow disini diartikan dengan kecepatan yang rendah

\section{Sensor Ultrasonik}

Sensor ultrasonik adalah sensor yang bekerja berdasarkan prinsip pantulan gelombang suara dan digunakan untuk mendeteksi keberadaan suatu objek tertentu di depannya, frekuensi kerjanya pada daerah di atas gelombang suara dari $40 \mathrm{KHz}$ hingga $400 \mathrm{KHz}$. Sensor ultrasonik terdiri dari dari dua unit, yaitu unit pemancar dan unit penerima. Struktur unit pemancar dan penerima sangatlah sederhana, sebuah kristal piezoelectric dihubungkan dengan mekanik jangkar dan hanya dihubungkan dengan diafragma penggetar. Tegangan bolak-balik yang memiliki frekuensi kerja 40 $\mathrm{KHz}-400 \mathrm{KHz}$ diberikan pada plat logam. Struktur atom dari kristal piezoelectric akan berkontraksi (mengikat), mengembang atau menyusut terhadap polaritas tegangan yang diberikan dan ini disebut dengan efek piezoelectric.

Kontraksi yang terjadi diteruskan ke diafragma penggetar sehingga terjadi gelombang ultrasonik yang dipancarkan ke udara (tempat sekitarnya). Pantulan gelombang ultrasonik akan terjadi bila ada objek tertentu dan pantulan gelombang ultrasonik akan diterima kembali oleh unit sensor penerima. Selanjutnya unit sensor penerima akan menyebabkan diafragma penggetar akan bergetar dan efek piezoelectric menghasilkan sebuah tegangan bolak-balik dengan frekuensi yang sama. Untuk lebih jelas tentang prinsip kerja dari sensor ultrasonik dapat dilihat prinsip dari sensor ultrasonic pada gambar 2.2 berikut :

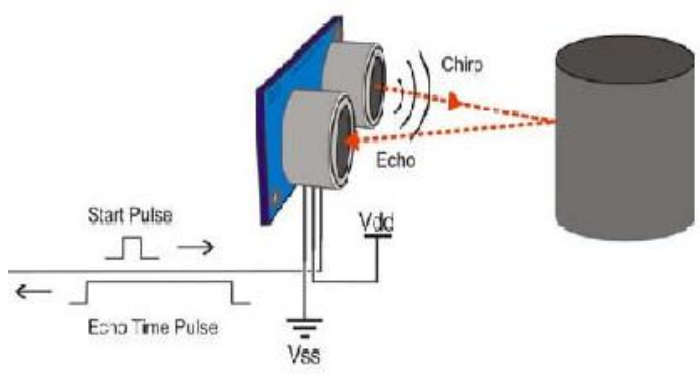




\section{Gambar 3. Prinsip kerja sensor} ultrasonik $^{1}$

Besar amplitudo sinyal elekrik yang dihasilkan unit sensor penerima tergantung dari jauh dekatnya objek yang dideteksi serta kualitas dari sensor pemancar dan sensor penerima. Proses sensoring yang dilakukan pada sensor ini menggunakan metode pantulan untuk menghitung jarak antara sensor dengan obyek sasaran. Jarak antara sensor tersebut dihitung dengan cara mengalikan setengah waktu yang digunakan oleh sinyal ultrasonik dalam perjalanannya dari rangkaian pengirim sampai diterima oleh rangkaian penerima, dengan kecepatan rambat dari sinyal ultrasonik tersebut pada media rambat yang digunakannya, yaitu udara. Prinsip pantulan dari sensor ulrasonik ini dapat dilihat pada gambar 2.3 sebagai berikut :

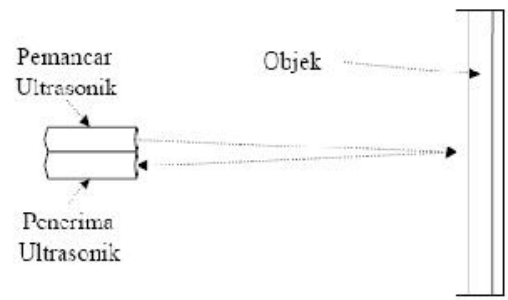

Gambar 4. Prinsip pemantulan sensor ultrasonik $^{2}$

Terdapat 3 jenis sensor ultraonik yang beredar di pasaran yaitu :

1 Sensor ultrasonik ping ( parallax )

2 Sensor ultrsonik defantech ( SRF 04 ranger )

3 Sensor ultrasonic DT. USIRR (Inovative Elektronic )

\section{METODE PENELITIAN}

Metodologi penulisan yang digunakan dalam menyelesaian skripsi ini adalah sebagai berikut:

1. Studi literature, yaitu dengan cara mengumpulkan data melalui informasi yang didapat dari buku, diktat dan internet sebagai media informasi paling aktual.

2. Studi eksperimen, yaitu dengan membuat alat dan melakukan pengujian langsung untuk mendapatkan suatu perangkat pengukuran yang lebih akurat.

\section{Perancangan Alat}

\section{* Perancangan Perangkat Keras.}

Dalam perancangan perangkat keras ini saya membuat mikrokontroler AVR dengan komponen utama sebagai IC nya adalah IC dari keluarga MCS51 yaitu AVR.Mikro AVR ini memiliki 40 keluaran atauoutputan dan inputan sebesar 5 Volt.Sensor ultrasonic digunakan untuk pendeteksi halangan jika ada sebuah pembatas atau halangan yg berada pada depan robot mau pun di samping kanan dan kiri, maka robot dapat menghindar menggunakan mikrokontroler ATmega8535 sebagai pemproses data, dan kemudian di tampilkan pada LCD $16 \times 2$.

1. Jenis pengendali yangdigunakan untuk robot beroda adalah mikrokontroler ATmega 8535.

2. Bahasa pemrograman yang dituliskan kedalam mikroprosessor pengendali adalah bahasa $c$ avr

3. Sensor ultrasonik digunakan sebagai masukan pengendali, yang berfungsi sebagai pendeteksi halangan disekitar robot beroda, sekaligus sebagai umpan balik sistem.

4. Aktuator menggunakan motor DC dengan menggunakan sistem pengendali aktuator Rangkaian Simulasi H Bridge.

- Perancangan Perangkat Lunak.

Dalam perancangan perangkat lunak ini saya menggukan bahasa Codevision AVR sebagai program yang akan dimasukkan kedalam mikrokontroler AVR.

\section{Pengujian Alat}

* Pengujian Perangkat Keras.

Dalam pengujian alat mikrokontroler pertama-tama adalah pengujian inputan dan outputnya benar-benar 5 Volt.Selanjutnya pengujian untuk mendownload program ke dalam IC AVR.Menguji sensor untuk dapat diolah di mikrokontroler, dan 
mengarah gerak robot menghindar dari penghalang yg berada disekitar robot.

\section{HASIL PENELITIAN DAN PEMBAHASAN}

Penjelasan tentang proses pengujian alat untuk memperoleh data-data hasil rancangan, dan untuk mengetahui apakah alat dapat bekerja dengan baik serta sesuai dengan spesifikasi yang diinginkan. Untuk menilai dan membuktikan kehandalan dari alat ini, maka dilakukan proses terakhir yaitu pengujian sistem dengan pengambilan data dari beberapa parameter uji, dan juga dilakukan analisa berdasarkan ketentuan yang ditetapkan oleh penulis, untuk mengetahui tingkat kehandalan dan kesalahan dari alat ini.

\section{Pengujian Fungsi Perangkat Keras}

a. Pengujian Langkah Kerja Motor DC Pengujian gerak motor adalah,dengan menghubungkan driver motor yang menggunakan Driver $\mathrm{H}$ bridge ke pin mikrokontroler port 1.0, sampai dengan port 1.4. Melalui program diberikan nilai logika tertentu kedriver motor, sehingga motor dapat bergerak searah jarum jam $($ Clock Wise $=C W)$, maupun berlawanan arah jarum jam (Contra Clock Wise $=C C W$ ). Kombinasi gerakan putaran motor kanan dan motor kiri berdasarkan logika yang diberikan, menyebabkan robot bergerak maju, mundur atau berbelok.

Hasil gerakan motor sesuai dengan logika yang diberikan, ditunjukkan oleh tabel 4.3. berikut :

Tabel 4.3. Hasil gerakan motor.

\begin{tabular}{|c|c|c|c|c|c|}
\hline \multicolumn{2}{|c|}{ Arah putaran } & $\begin{array}{c}\text { Kondisi logika pada } \\
\text { masing-masing } \\
\text { pin(I/O) }\end{array}$ \\
\hline $\begin{array}{c}\text { Motor } \\
\text { kiri }\end{array}$ & $\begin{array}{c}\text { Motor } \\
\text { kanan }\end{array}$ & .0 & .1 & .2 & .3 \\
\hline CW & off & 1 & 0 & 0 & 0 \\
\hline off & CW & 0 & 0 & 0 & 1 \\
\hline CW & CW & 1 & 0 & 0 & 1 \\
\hline CCW & CCW & 0 & 1 & 1 & 0 \\
\hline off & off & 0 & 0 & 0 & 0 \\
\hline
\end{tabular}

\section{b. Pengujian fungsi perangkat lunak}

Pengujian fungsi perangkat lunak ini dilakukan untuk mengetahui fungsi alat, dimana dalam pengujian fungsi sistem tersebut dibagi menjadi 2 tahap pengujian, yaitu pengujian program pada masing-masing robot berbasis Atmega8535 dengan sensor ultrasonik, dan pengujian program secara keseluruhan.

\section{c. Pengujian Sensor Ultrasonik}

Langkah pengujian sensor Ultrasonik adalah sebagai berikut:

1. Menghubungkan catu daya $5 \mathrm{~V}$ pada signal SIG sensor Ultrasonik.

2. Menghidupkan rangkaian mikrokontroler yang telah diprogram, untuk menguji sensor ultrasonik dan mematikan rangkaian aplikasi yang lain.

3. Mengukur jarak deteksi sensor, pada jarak antara objek dengan sensor ultrasonik saat sensor ultrasonic terhalang atau tidak terhalang.

4. Melakukan pengujian dengan media yang berbeda, untuk mengetahui kualitas sensor tersebut.

\section{Pengambilan Data Ukur}

Penjelasan proses pengujian alat untuk memperoleh data-data hasil rancangan, dan untuk mengetahui apakah alat dapat bekerja dengan baik, serta sesuai dengan spesifikasi yang diinginkan. Untuk menilai dan membuktikan kehandalan dari alat ini, maka dilakukan proses terakhir yaitu pengujian sistem, dengan pengambilan data dari beberapa parameter uji, dan juga dilakukan analisa berdasarkan ketentuan yang ditetapkan oleh penulis, untuk mengetahui tingkat kehandalan dan kesalahan dari rancang bangun robot penghindar halangan.

Pengujian alat ini mencakup beberapa tahap pengukuran atau pengujian, yang antara lain :

A. Pengujian fungsi perangkat keras, yaitu

1) Pengujian sensor ultra sonic.

2) Pengujian langkah kerja motor dc.

B. Pengujian fungsi perangkat lunak, yaitu : 
1) Pengujian program C-AVR pada masing-masing robot penghindar halangan.

2) Pengujian program C-AVR keseluruhan.

C. Pengambilan data ukur.

Berikut adalah alat yang digunakan untuk melakukan pengujian:

1) Komputer atau laptop dengan software C-AVR.

2) Multimeter digital.

3) Kabel penghubung.

4) Tabel pencatat data.

Hasil pengujian:

1. Pertama kali alat dihidupkan (hardware) dengan menggunakan battery.dan mikrokontroler menyala.

2. Hasil pengujian dapat terlihat ketika robot berjalan danketika ada haling dengan jarak yg sudah ditentukan, maka robot akan menghndari halangan yg ada disekitar sensor, seperti terlihat pada tabel 4.1. dibawah ini:

Tabel4.1 Pengukuran jarak sensor ultrasonic.

\begin{tabular}{|c|c|c|c|c|c|}
\hline \multirow{2}{*}{ No } & \multirow{2}{*}{$\begin{array}{c}\text { Media yang } \\
\text { digunakan } \\
(\text { objek })\end{array}$} & $\begin{array}{c}\text { kisaran } \\
\text { maksimal } \\
(\mathrm{cm})\end{array}$ & $\begin{array}{c}\text { kisaran } \\
\text { minimum } \\
(\mathrm{cm})\end{array}$ & $\begin{array}{c}\text { sensor kanan } \\
\text { kisaran } \\
\text { maksimal } \\
(\mathrm{cm})\end{array}$ & $\begin{array}{c}\text { kisaran } \\
\text { minimum } \\
(\mathrm{cm})\end{array}$ \\
\hline 1 & Dinding & 256 & 4,3 & 235 & 3,5 \\
\hline 2 & Papan / Kayu & 185 & 4,2 & 195 & 2,9 \\
\hline 3 & Steroform & $\begin{array}{c}\text { tidak } \\
\text { dipantulkan }\end{array}$ & $\begin{array}{c}\text { tidak } \\
\text { dipantulk } \\
\text { an }\end{array}$ & $\begin{array}{c}\text { tidak } \\
\text { dipantulk } \\
\text { an }\end{array}$ & $\begin{array}{c}\text { tidak } \\
\text { dipantulk } \\
\text { an }\end{array}$ \\
\hline 4 & plastik & $\begin{array}{c}\text { tidak } \\
\text { dipantulkan }\end{array}$ & $\begin{array}{c}\text { tidak } \\
\text { dipantulk } \\
\text { an }\end{array}$ & $\begin{array}{c}\text { tidak } \\
\text { dipantulk } \\
\text { an }\end{array}$ & $\begin{array}{c}\text { tidak } \\
\text { dipantulk } \\
\text { an }\end{array}$ \\
\hline
\end{tabular}

Data-data hasil pengukuran jarak sensor ultrasonic, digunakan untuk proses kinerja robot. Data jarak dari sensor ultrasonic, akan digunakan untuk acuan bagi robot dalam menentukan arah belokan, sehingga robot tidak dapat menabrak saat terdapat halangan yang menghambat laju robot tersebut.

\section{KESIMPULAN DAN SARAN}

\section{Kesimpulan}

Dari hasil analisa terhadap sistem rancang bangun robot beroda penghindar halangan, maka dapat diambil kesimpulan sebagai berikut :

1. Rancang bangun penghindar halangan berjalan sebagai mana mestinya seperti yangdiinginkan.

2. Hasil dari pengujian dan analisis dari program dan hardware dapat diambil kesimpulan bahwa, keduanya dapat berkomunikasi dengan benar dan dapat mengeluarkan nilai yang benar.

3. Hasil pengiriman data dari sensor ultrasonic ke mikrokontroler, mikrokontroler ke rangkian $\mathrm{H}$ bridge, dan LCD sesuai dengan batasan yang telah ditentukan.

\section{UCAPAN TERIMAKASIH}

ucapan terimakasih disampaikan kepada pemberi dana serta personal yang mendukung terlaksananya penelitian dan penulisan.ucapan terimakasih

\section{DAFTAR PUSTAKA}

1. Agus Bejo, 2008, "Rahasia Kemudahaan Bahasa C dan Mikrokontroler ATMega8535", Graha Ilmu, Yogyakarta.

2. Ardi Winoto, 2008, "Mikrokontroler AVR ATmega8/32/16/8535 dan Pemogramannya dengan Bahasa C pada WinAVR", Penerbit INFORMATIKA Bandung.

3. Creative Vision,......, "Panduan Manual MA-8535 V2.0", diakses tanggal 4 
September 2012, dari

www.mikron123.com.

4. Iswanto, 2009, "Belajar Sendiri

Mikrokontroler AT90S2313 dengan

BASIC Compiler", ANDI, Yogyakarta.

5. MicroCamp2.0 ATmega8 Activity Kit

Manual,............., diakses tanggal 25

Januari 2012, dari www.inexglobal.com.

6. Makhsun, 2011, "Modul Aplikasi

Mikrokontroler", Universitas Pamulang.

7. Proposal Tugas Akhir, diakses tanggal 25

Januari 2012, dari

http://www.elektro.undip.ac.id/wpcont

ent/uploads/2009/05/proposalTugasAk

hir.pdf.

8. Setiawan. Arif, 2011, "20 Aplikasi

Mikrokontroler ATMega8535 \&

ATMega16 BASCOM-AVR", Penerbit

ANDI, Yogyakarta. 